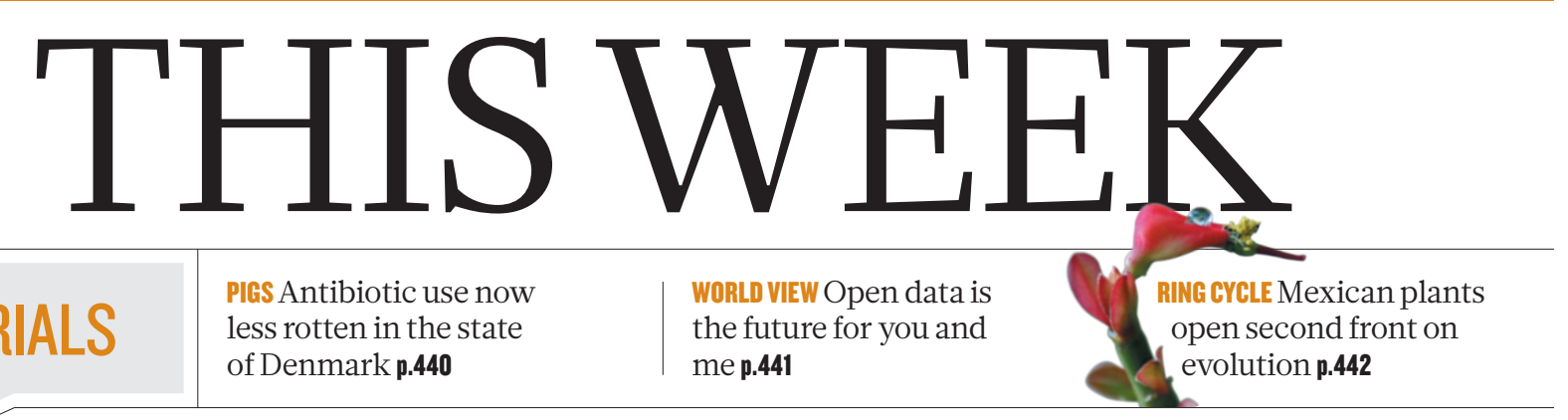

EDITORIALS less rotten in the state of Denmark p.440 the future for you and me p.441

\title{
Openness costs
}

\author{
Two reports highlight key aspects of the global trend towards open access to research results: \\ who will pay, and how much, to supply what to whom?
}

$\mathrm{B}$ ritain has become involved in something of a national debate recently over access to the research literature. And within the past week, two reports have appeared that will be relevant to researchers everywhere. The Royal Society published an analysis of openness in scientific data (see go.nature.com/of89t1 and page 441). And a committee set up by the UK government reported on how access could be enhanced, and how policy-makers could promote a gradual shift towards publishing research papers in journals that allow or require authors to pay article publishing charges (APCs) up front. The published paper would then be freely available to all from the moment of publication. That is a shift that Nature in principle supports (see Nature 481, 409; 2012).

The UK government's report, widely referred to as the Finch report after Janet Finch, who chaired the committee that delivered it, examines in depth the issues facing the United Kingdom (see go.nature. $\mathrm{com} /$ solui2). The country's funding structure in principle enables it more readily than many to shift some of the funds currently spent on university library subscriptions to a stream for APCs partly funded by research funding councils.

The report is also timely in an international context, because funders elsewhere are thinking about this transition. All are aware of the complexities that Finch highlights, and in practice it may take several years for progress to be made towards mandated open access. But the mood to make the shift is strong.

A key issue is the cost of publishing, and here the parallels between the Finch report and the Royal Society report (whose authors include Nature's editor-in-chief) are striking. Both make the point that scientific output, whether research papers or research data, needs to be rendered usable, and that the costs of curation, hosting, editing and enrichment with metadata, and the continual renewal of such activities, must all be met.

In its advocacy of open data, the Royal Society report does not estimate potential costs but provides examples of their likely scale. The preprint server arXiv, which does little more than host papers sent to it in raw form, requires six full-time staff. The Worldwide Protein Databank and the UK Data Archive each require a multimillion-dollar budget and around 65 full-time staff. (By acute contrast, a survey of UK universities revealed that they deploy on average 1.4 full-time staff to run their institutional repositories, and that only $40 \%$ of such repositories receive research data.)

The Finch report's attention to national financial models provides an important component for debate. The report models (albeit with highly uncertain assumptions) scenarios in a transition that includes both subscriptions and author-paid open access, also taking into account assumed international shifts in policy. UK researchers publish well over 100,000 articles a year. In one example, assuming that $50 \%$ of these are published fully open access at an average APC of $£ 1,450$ (US\$2,260), the transition would be cost-neutral to the United Kingdom. Under more pessimistic assumptions about international

uptake, and if the average APC were $£ 2,200$, the additional cost to the UK higher-education sector is estimated at $£ 70$ million, in a current annual expenditure on journals of $£ 175$ million in a research budget of more than $£ 5$ billion. (Papers published in highly selective journals such as Nature, whose costs would point towards much higher APCs, would represent a small proportion of the national output.)

Publishers in such an environment will need all the more to demonstrate that they add value to the research process. This sits alongside their

"The mood to make the shift towards mandated open access is strong."

understanding of the value they add is weak. develop trust amid a fundamental shift in their customer base.

The transition poses a particular challenge to universities. The Finch report rightly concludes that universities will need to set up dedicated funds for APCs. Issues of principle and practice in the deployment of such funds will take time to become established, especially in highly decentralized universities. As the number of papers published by their researchers has increased over the past few years, so the proportion of university funds devoted to libraries has declined. And yet, as the Royal Society report clearly demonstrates, the information obligations of these institutions, both internal and external, can only grow.

\section{A first step}

\section{Perhaps the Earth conference was not a wasted opportunity but the start of a new journey.}

$\mathrm{T}$ The agreement for modest commitments to sustainable development after 2015, reached at last week's Earth conference in Rio de Janeiro, has been roundly condemned as inadequate, or even an outright failure. The document is full of legalese and vague assertions, and it postpones the making of potentially significant decisions and assigning accountability to an uncertain future. When it comes to sustainable development, the agreement neither secures new resources nor defines the parameters for success. But did anybody, really, expect more?

Rio was never intended as a venue for the signing of major new environmental treaties, so it should come as no surprise that governments did not do so. But the actual purpose of the conference was never made 